\title{
Multi-scale spatial sensitivity analysis of a model for economic appraisal of flood risk management policies
}

\author{
Nathalie Saint-Geours ${ }^{\mathrm{a},}{ }^{*}$, Jean-Stephane Bailly ${ }^{\mathrm{a}, \mathrm{b}}$, Frede ric Grelot ${ }^{\mathrm{c}}$, Christian Lavergne ${ }^{\mathrm{d}}$ \\ ${ }^{a}$ Irstea, UMR TETIS, 500 rue J.F. Breton BP 5095, F-34196 Montpellier, France \\ b AgroParisTech, UMR LISAH, 2 place Pierre Viala, F-34060 Montpellier, France \\ ${ }^{c}$ Irstea, UMR G-EAU, 361 rue J.F. Breton BP 5095, F-34196 Montpellier, France \\ ${ }^{\mathrm{d}}$ Universite Montpellier 3, I3M, Montpellier, France
}

Software availability

Name of software: NOE

Description: The NOE model computes expected annual flood damages at the scale of individual flood-exposed assets, from a given situation, i.e. from a land use map, a set of water depth maps, and a set of depthedamage curves. It also computes expected annual avoided damages at the same scale, when comparing one situation with another. Developers: N. Saint-Geours, T. Langer, F. Grelot and J.-S. Bailly Source language: Python (arcpy library) and $\mathrm{R}$

Software required: ArcGIS ${ }^{\odot}$

Availability: Contact the developers

\section{Introduction}

Among the numerical models which are used to investigate environmental issues, many rely on spatially distributed data, such as Digital Terrain Models (DTM), soil maps, land use maps, etc. These spatially distributed models, or simply spatial models, allow for an explicit description of the spatial structures, spatial interdependencies, and spatial dynamics involved in the physical, biological, or anthropogenic processes under study. However, it is now well known that all numerical modelsdincluding spatially distributed onesdare fraught with uncertainties, which may stem from a lack of knowledge about the phenomena under study, from the natural variability of the quantities of interest, from measurement errors, model assumptions, or numerical approximations (Walker et al., 2003). Hence, when a spatial model is used as a support tool for decision-making, one must remember that "anyone using uncertain informationdmeaning the overwhelming majority of mapped data usersdshould consider carefully the possible sources of uncertainty and how to deal with them" (Fisher et al., 2005).

To address this issue, a number of uncertainty analysis (UA) and sensitivity analysis (SA) methods, both qualitative and quantitative, 
have been developed over the last decade (Saltelli et al., 2008). They study how model outputs react when input variables are uncertain. UA focuses on the propagation of uncertainties throughout the model and aims to quantify the resulting variability of the model output. SA seeks to study how the uncertainty in a model output can be apportioned to the uncertainties in each of the model inputs. It allows input variables to be ranked according to their contribution to the output variability. SA thus helps to identify the key input variables, those that determine the final decision of the model enduser, and on which further research should be carried out. UA and SA methods have been gradually adopted by modellers in different disciplinary fields, especially in environmental research (Ascough et al., 2008; Cariboni et al., 2007; Tarantola et al., 2002), and today are widely recognized as essential steps in model building (CREM, 2009; European Commission, 2009). One of the most common SA approach is variance-based global sensitivity analysis (VB-GSA), which widely explores the space of input uncertainties (global method), and does not require any preliminary hypothesis (linearity, regularity) regarding the model under study (Saltelli et al., 2008).

However, partly because of the curse of dimensionality, SA methods have seldom been applied to environmental models with both spatially distributed inputs and outputs. A few recent works have tried to tackle this issue (Lilburne and Tarantola, 2009, for a review). Both Ruffo et al. (2006) and Saint-Geours et al. (2013) used geostatistics to simulate the uncertainty on spatially distributed model inputs and incorporate them into a VB-GSA approach. Moreau et al. (2013) investigated the sensitivity of the agrohydrological TNT2 model to five different soil-map patterns, making use of a fractional factorial design to carry out an analysis of variance, while Chen et al. (2013) recently discussed sensitivity analysis for spatial multi-criteria decision making models. In addition, other authors developed new procedures to compute sensitivity indices for a spatial model output, either with respect to its spatial average (Lilburne and Tarantola, 2009) or with respect to the values of the model output at each point of a study area (Heuvelink et al., 2010; Marrel et al., 2011). A number of recent papers also deal with the issue of CPU time expensive environmental models, for which standard sensitivity analysis techniques cannot be applied; in this case, the construction of a cheap metamodel (emulator) is often necessary, see (Petropoulos et al., 2013) for a recent illustration on the SimSphere soilevegetationeatmosphere-transfer model. The design of such meta-models for expensive computer codes with spatially distributed inputs and outputs is still an open research question (Marrel et al., 2011).

Nevertheless, to date, none of these studies has reported on a key question: the link between UA/SA and spatial scale issues. Indeed, in many environmental models, the end users are interested in the aggregated value of some spatially distributed model output over a given spatial unit v. In most cases, the aggregated value is just the linear average or the sum of model output over $v$ (e.g., the average porosity of a block, the total evapotranspiration over a plot of land, etc.). But Heuvelink (1998) observed that under a change of spatial support $\mathrm{v}$, the relative contribution of uncertain model inputs to the variability of the aggregated model output may change. Hence, in a spatial model, the results of UA/SA depend on the spatial scale of the problem. Unfortunately, the notion of spatial scaledmade up of the scale triplet (B16schl and Sivapalan, 1995): spatial extent, support, spacingdis mostly ignored in the mathematical frameworks of SA methods. Among scale issues, the socalled change of support problem has long been discussed in the field of geostatistics: we know that the variance of an uncertain spatially distributed quantity depends on the spatial support v over which it is aggregated. Up to our knowledge, only Saint-Geours et al. (2012) tried to translate this problem into the context of variance-based GSA. On a simple model, they showed how the sensitivity indices of model inputs depend on the spatial support $v$ over which the model output is aggregated; denoting with $\mathrm{p}(\mathrm{v})$ the ratio of sensitivity indices of spatially distributed model inputs vs non-spatial inputs, they found a relation of the form $\mathrm{p}(\mathrm{v}){ }^{1 / 4} \mathrm{v}_{\mathrm{c}} / \mathrm{jvj}$, with jvj the surface area of $v$ and $v_{c}$ some critical value. When the model output is aggregated on a spatial support of area jvj smaller than $v_{c}$, the ratio $p(v)$ is larger than 1 , which means that the sensitivity indices of spatially distributed inputs are larger than those of non-spatial inputs, and thus that spatially distributed inputs contribute more to the variance of model output than nonspatial inputs. On the contrary, if $\mathrm{jvj}$ is larger than $\mathrm{v}_{\mathrm{c}}$, then $\mathrm{p}(\mathrm{v}) \quad 1$, and the non-spatial inputs are key contributors to model output variability. However, their work was mainly theoretical, and their results only valid under restrictive assumptions of inputs stationarity and model additivity. In particular, they did not examine if their conclusions would hold on a real, complex test case.

The aim of this paper is thus to investigate, on an applied case study, how the results of an uncertainty and sensitivity analysis interact with a change of spatial support of the model output. We discuss this question through a complete case study on a model for economic assessment of flood risk management policies, named NOE (Saint-Geours et al., 2013). The NOE model has both spatially distributed inputs (topography, map of water heights, land use map, etc.), and spatially distributed outputs (avoided flood damage indicators). A number of recent studies already performed UA/SA of flood damage assessment models, in whole or in parts (Apel et al., 2008). Most of these studies are limited to the forward propagation of uncertainty (UA), the perimeter of which can vary from a single module of the complete modelde.g., land use (Te Linde et al., 2011), hydraulic simulation (Bales and Wagner, 2009), estimation of damages (Koivum€̂ki et al., 2010)dup to the entire modelling chain (de Kort and Booij, 2007; Qi and Altinakar, 2011). Fewer publications address the issue of ranking the various sources of uncertainty with SA (de Moel et al., 2012). In particular, Saint-Geours et al. (2013) already carried out VB-GSA on the NOE model over the Orb Delta, France. However, in this study, they disregarded spatial scale issues: sensitivity indices were only computed with respect to the aggregated value of model output over the entire floodplain, without examining model behaviour at finer spatial scales. There are at least two motivations for an in-depth study of this issue. First, it would bring a better understanding of the behaviour of the NOE model, by identifying the key input variables at different spatial scales. Next, analysing the uncertainty and sensitivity of NOE model outputs at different spatial scales would provide the model endusers (i.e., local water managers) with a more complete information and may help them in their decision making.

In order to demonstrate how UA/SA can bring a new insight into scaling issues in spatial modelling, we perform a multi-scale VB-GSA of the NOE model. Our idea is to compute variance-based sensitivity indices with respect to the NOE outputs aggregated over different spatial supports $\mathrm{v}$. We will try to answer the following questions: what is the uncertainty of the NOE output, at different spatial scales? What are the key input variables that explain the largest fraction of the variance of the NOE output, at different spatial scales? How does the uncertainty of the NOE output, and the related sensitivity indices, vary in space, at a fixed spatial scale?

The next section (Section 2) starts with some relevant background information on the selected study site (the Orb Delta), and presents the NOE model. Next, we display a brief introduction to the concepts of VB-GSA, and portray into details how we simulated the uncertainty sources in the NOE model, propagated them with Monte-Carlo simulations, and how we computed multi-scale variance-based sensitivity indices (Section 3). The results consist of 


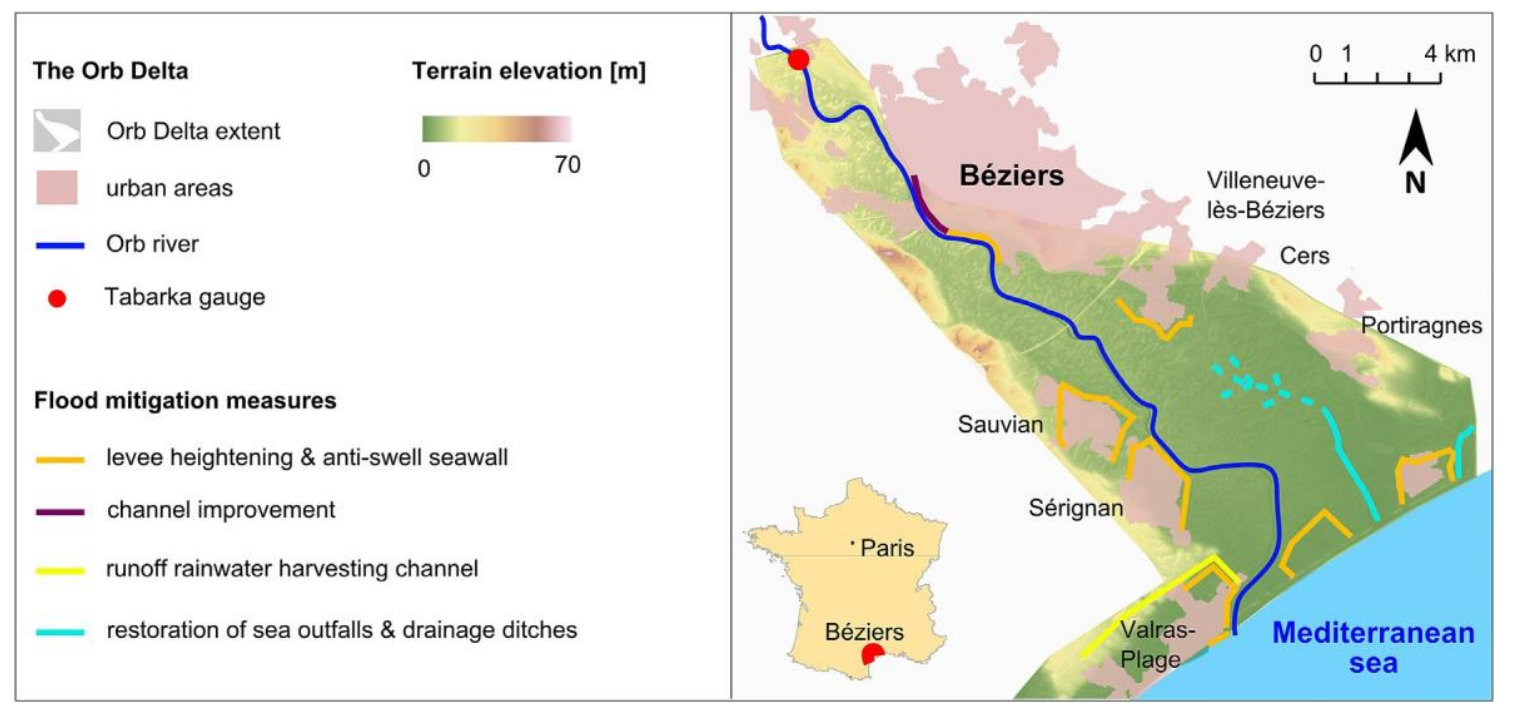

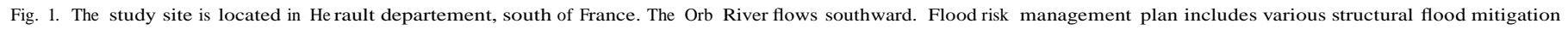
measures.

both uncertainty maps and sensitivity maps that allow us to identify the key input variables in the NOE model at different spatial scales (Section 4). We discuss the main outcomes and limits of our study in Section 5.

\section{The NOE model, study site and data}

The NOE model and its implementation on the Orb Delta, France, were already fully described by Saint-Geours et al. (2013). In this section, we only reproduce the key points that are necessary to the understanding of our present work.

\subsection{Study site: the Orb Delta}

The Orb Delta is a catchment of 63 sq. km located in the south of France, surrounding a $15 \mathrm{~km}$ reach of the Lower Orb River from Beziers city to the Mediterranean sea (Fig. 1). It has a typical Mediterranean subhumid regime, with an annual maximum discharge ranging from 100 to $1800 \mathrm{~m}^{3} / \mathrm{s}$ from year to year at the main gauging station on the Delta (Tabarka gauge, Fig. 1). The Orb Delta includes the cities of Beziers, Portiragnes, Sauvian, Se rignan, Valras-Plage and Villeneuve-les-Be ziers. It is covered for one third by cultivated land. About 16,000 people live permanently in the flood prone area, which also hosts 774 companies and 30 seaside campgrounds, gathering up to 100,000 tourists in summertime. In December 1995, a flooding event with a peak discharge of $1700 \mathrm{~m}^{3} / \mathrm{s}$ at Tabarka gauge caused around 53 MV in material losses (Erdlenbruch et al., 2008). In 2001, local authorities reacted and launched a flood risk management project, mainly based on various structural mitigation measures, including dyke strengthening around urban areas, restoration of sea outfalls and channel hydraulic improvement (SMVOL, 2011). Available data on the area include aerial photographs, a 5 m-cell-size DTM built from photogrammetry, the annual maximum flow series from 1967 to 2009 at the Tabarka gauge (referred to as the AMFS dataset), and various spatial datasets on buildings, cultivated land and economic activities.

\subsection{The NOE model}

The NOE model is used to estimate the flood damage reduction which will result from the implementation of flood mitigation measures on the Orb Delta. It is a combination of hydrological,

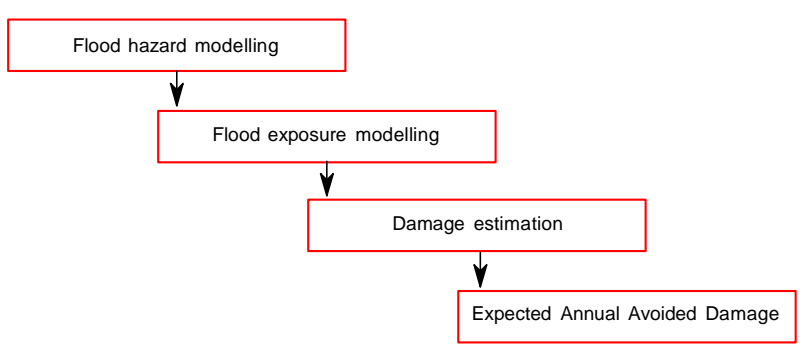

Fig. 2. Simplified flowchart of the NOE model.

hydraulic, GIS and economic modules. ${ }^{1}$ The main model output is the Expected Annual Avoided Damage (DEAD [V/year]) over the floodplain, that is, the amount of annual expected flood losses that will be reduced thanks to the flood mitigation measures. We briefly present here the main processes of the NOE model (Fig. 2).

\subsubsection{Flood hazard modelling}

The DEAD indicator is computed from a range of six potential flood events of various magnitudes, denoted by $\mathrm{e}_{1} \mathrm{ee}_{6}$, with increasing maximum discharges $\mathrm{q}_{1} \mathrm{eq}_{6}$ (Table 1). These flood events include both historical floods $\left(\mathrm{e}_{3}, \mathrm{e}_{4}\right)$, and floods which were simulated with a rainfallerunoff model $\left(\mathrm{e}_{1}, \mathrm{e}_{2}, \mathrm{e}_{5}, \mathrm{e}_{6}\right)$. Their annual exceedance frequencies $f_{1} e f_{6}$ were computed from the AMFS dataset, which was fitted by a Gumbel dischargeefrequency curve. Next, for each flood event $e_{i}, i \frac{1}{4} 1, \ldots, 6$, the water flow over the floodplain was simulated using Isis Flow, a 1D step-backwater hydraulic model (ISIS, 2012). These flow simulations were then combined with the DTM, to produce maps of maximum water depths over the Orb Delta. These computations were carried out both before and after the enforcement of flood mitigation measures.

\subsubsection{Flood exposure modelling}

To carry out flood exposure analysis, a detailed land use geodatabasedreferred to as the assets mapdof the entire Orb Delta was built from various data sources (Fig. 3). Four types of flood-

\footnotetext{
1 It must be emphasized that the NOE model is just one possible implementation of a wider, more generic framework for flood damage assessment, that has been used by many authors on various floodplains around Europe (Merz et al., 2010).
} 
Table 1

Main characteristics of flood events $\mathrm{e}_{1}$ to $\mathrm{e}_{6}$ : maximum discharge $\mathrm{q}$ at Tabarka gauge, annual exceedance frequency $\mathrm{f}$, and corresponding return interval $\mathrm{T} 1 / 4$ 1/f.

\begin{tabular}{|c|c|c|c|c|}
\hline & Flood event description & $\mathrm{q}\left[\mathrm{m}^{3} / \mathrm{s}\right]$ & $\mathrm{f}$ & $\mathrm{T}$ [years] \\
\hline $\mathrm{e}_{1}$ & Smallest event $^{\mathrm{a}}$ & 1018 & 0.2 & 5 \\
\hline$e_{2}$ & 10-Year design flood & 1287 & 0.1 & 10 \\
\hline$e_{3}$ & Historical flood (Dec. 1987) & 1696 & 0.0333 & 30 \\
\hline $\mathrm{e}_{4}$ & Historical flood (Jan. 1996) & 1882 & 0.02 & 50 \\
\hline$e_{5}$ & Large design flood & 2133 & 0.01 & 100 \\
\hline $\mathrm{e}_{6}$ & Extreme flood $^{\mathrm{b}}$ & 3000 & 0.001 & 1000 \\
\hline
\end{tabular}

a Event $\mathrm{e}_{1}$ is supposed to be the smallest flood event for which damages occur.

exposed assets are considered: private housing units (individual buildings), plots of cultivated land, campgrounds, and other economic activities. The assets map describes each asset by an individual polygonal object in a GIS vector layer at the 1:5000 scale (Table 2), and each object is further characterized by its subtype, its ground floor elevation, its floor surface area, etc. Flood exposure is assessed by overlaying the assets map with water depth maps, and by computing the average water depth over each individual polygonal object.

\subsubsection{Damage estimation}

In this study, flood damage assessment only includes direct and tangible monetary lossesdMerz et al. (2010) list the other types of flood-induced damages that should be considered for a more complete analysis. For each flood event $\mathrm{e}_{1} \mathrm{ee}_{6}$, the total damage cost before (resp. after) the enforcement of flood mitigation measures is denoted by $\mathrm{D}_{\mathrm{i}}\left(\right.$ resp. $\mathrm{D}_{\mathrm{i}}^{0}$ ), and $\mathrm{DD}_{\mathrm{i}} 1^{1 / 4} \mathrm{D}_{\mathrm{i}} \quad \mathrm{D}_{\mathrm{i}}^{0}$ denotes the damage reduction brought by the mitigation measures. Damage estimates are computed for each flood-exposed asset from flood exposure data, using a set of 94 depthedamage curves, one for each combination of type, subtype of assets and season of flood occurrence (SMVOL, 2011). These depthedamage curves link the average water depth over the asset with a value of damage per unit area of floor surface [V/sq.m.]dfor cultivated land, private housing, and campgroundsdor with a total value of damage [V] d for other economic activities. As a coarse approximation, flood velocity and flood duration were considered to be homogeneous over the entire study area.
Table 2

Content of the assets map.

\begin{tabular}{lcc}
\hline Type of assets & \# objects & Total surface [sq. km] \\
\hline Private housing & 16,436 & 1.37 \\
Cultivated land & 707 & 23.36 \\
Campgrounds & 111 & 1.02 \\
Other economic activities & 691 & 0.62 \\
\hline
\end{tabular}

2.2.4. Computation of the expected annual avoided damage

The expected annual damage (EAD [V/year]) is a common indicator used to measure potential flood damages over a given floodplain (Arnell, 1989). It can be defined as the mathematical expectation of flood damages $\mathrm{D}(\mathrm{e})$ over the space of possible flood events e. Using the annual exceedance frequencies $f$ of flood events, we have: EAD ${ }^{1 / 4}{ }_{0}^{1}$ Dðf Pdf (resp. EAD ${ }^{0}{ }_{0}^{1 / 4} D^{0}$ ðf Pdf). This integral can be approximated with a simple trapezoidal ruledamong other integration methodsdfrom the range of flood events $\mathrm{e}_{1} \mathrm{ee}_{6}$ with annual exceedance frequencies $\mathrm{f}_{1} \mathbf{e f}_{6}$ and corresponding damages $\mathrm{D}_{1} \mathrm{eD}_{6}$ (resp. $\mathrm{D}_{1}^{0}$ to $\mathrm{D}_{6}^{0}$ ). In the present study, the main output of interest is the reduction of potential flood damages that will result from the enforcement of flood mitigation measures on the Orb Delta, i.e., the variation:

\section{DEAD $1 / 4$ EAD EAD $^{0}$}

One key point is that the DEAD indicator [V/year] can be displayed at different spatial scales. It is first computed for each individual asset over the floodplain, and mapped, but it can also be summed up over any spatial unit v (e.g., an administrative district within the floodplain), or even aggregated over the entire Orb Delta.

\section{Methods}

\subsection{Overview}

Multi-scale VB-GSA of the NOE model aims to assess the uncertainty of the DEAD indicator, to compute the associated variance-based sensitivity indices, and to investigate: i) how these uncertainty and sensitivity measures depend on the spatial support

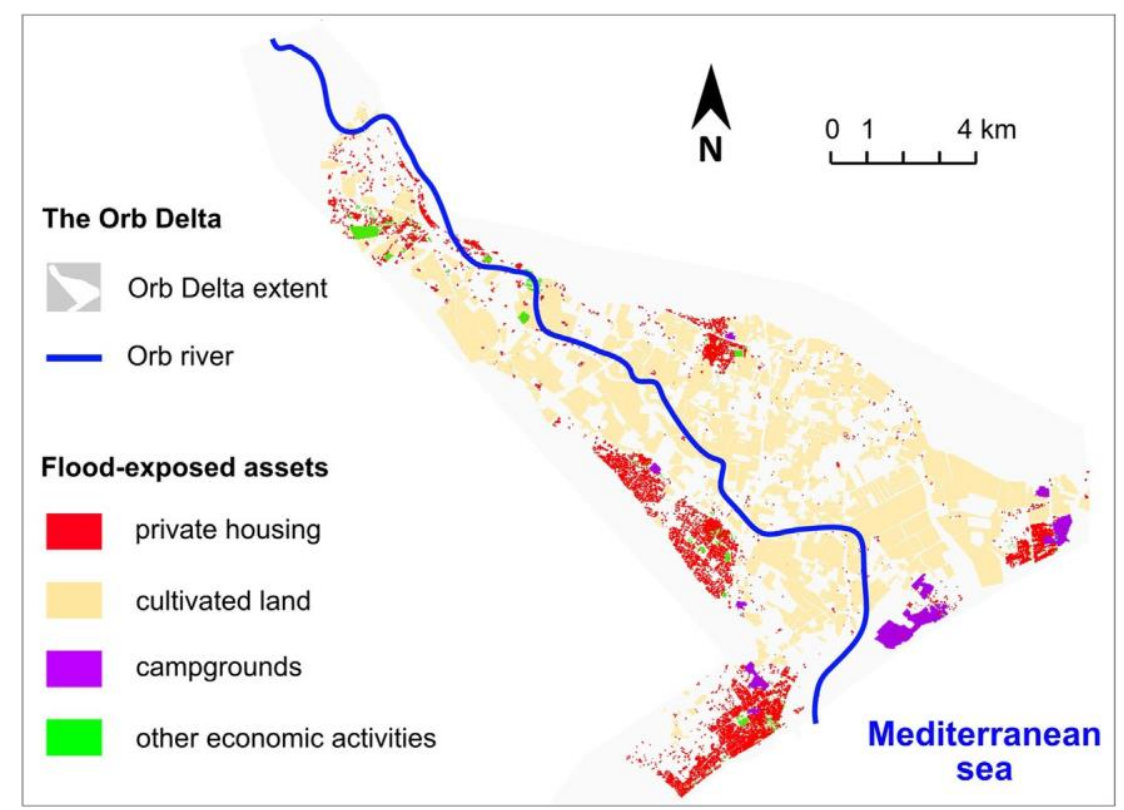

Fig. 3. The assets map describes each asset by an individual polygonal object in a GIS vector layer at the 1:5000 scale. 


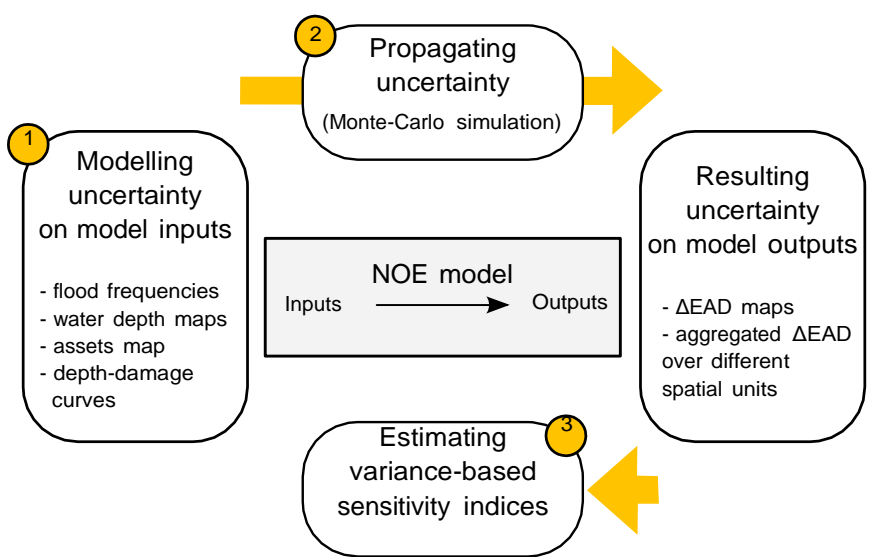

Fig. 4. Flowchart for multi-scale VB-GSA of the NOE model.

of the DEAD indicator; and ii) how they vary in space, for a fixed output scale. In the first step of the analysis (Fig. 4), sources of uncertainty in the NOE model are identified and described in a probabilistic framework, and a set of random realisations is sampled for each uncertain model input (Section 3.2). Next, pseudo-Monte Carlo simulations are used to explore the space of input uncertainty and propagate uncertainty through the NOE model (Section 3.3). Variance-based sensitivity indices are then computed to rank the uncertain model inputs, depending on their contribution to the variance of the DEAD indicator (Section 3.4). These steps were already presented in a single-scale VB-GSA of the NOE model (Saint-Geours et al., 2013), thus we only reproduce here the key elements that are necessary to the understanding of the present work. We then go one step further, by computing sensitivity indices in a multi-scale framework (Section 3.5): sensitivity indices are computed with respect to the aggregated value of the DEAD output indicator over cells of different sizes. For each cell size, we compute both uncertainty maps and sensitivity maps, that allow us to discuss the relation between VB-GSA and spatial scale issues.

\subsection{Modelling sources of uncertainty}

The first step of the analysis is to list the uncertainty sources in the NOE model, then to describe and simulate them in a probabilistic setting, using residual analysis, external data or expert opinion. Four uncertain inputs are considered (Table 3): the flood annual exceedance frequencies $\left(\mathrm{X}_{1}\right)$, the assets map $\left(\mathrm{X}_{2}\right)$, the water depth maps $\left(\mathrm{X}_{3}\right)$, and the depthedamage curves $\left(\mathrm{X}_{4}\right)$. A set of $n_{j} 1 / 4100 e 1000$ random realisations is sampled for each of them.

\subsubsection{Uncertainty in flood annual exceedance frequencies $\left(\mathrm{X}_{1}\right)$}

Uncertainty in the computation of flood annual exceedance frequencies $f_{i}$ may arise from stream gauge measurement errors, non-stationarity of hydrologic series due to climate change, but also from the choice of an extreme value distribution to fit a dischargeefrequency relationship to the AMFS dataset, and from the statistical uncertainty of this fit. Here, only the latter uncertainty was taken into account, which we acknowledge is only a small part of the overall uncertainty in $\mathrm{f}_{\mathrm{i}}$. Empirical confidence bounds (Fig. 5) were computed around the nominal Gumbel curve fitted on the AMFS dataset (Maidment, 1993), and a set of $n_{1} 1 / 410^{3}$ Gumbel curves were then randomly sampled from the joint distribution of the fitted parameters. From this set of curves, $\mathrm{n}_{1} 1 / 410^{3}$ exceedance frequencies $f_{i}$, and associated return intervals $T_{i} 1 / 41 / f_{i}$, were generated for each flood event $e_{i}, i \frac{1}{4} 1, \ldots, 6$ (Fig. 6), with an additional white noise following normal distribution $\mathrm{N} \partial 0 ; \mathrm{s}^{2} \mathrm{P}$ with $\mathrm{s}^{2}$ the empirical standard deviation of residuals.
Table 3

Sources of uncertainty in the NOE model. A set of $n_{j}$ random realisations is sampled for each uncertain input $\mathrm{X}_{\mathrm{j}}$.

\begin{tabular}{|c|c|c|c|}
\hline & Model input & $\mathrm{n}_{\mathrm{j}}^{\mathrm{a}}$ & Model of uncertainty \\
\hline $\mathrm{X}_{1}$ & $\begin{array}{l}\text { Exceedance } \\
\text { frequencies }\end{array}$ & 1000 & $\begin{array}{l}\text { Confidence interval on } \\
\text { the fitted Gumbel } \\
\text { dischargeefrequency } \\
\text { curve. }\end{array}$ \\
\hline $\mathrm{X}_{2}$ & $\begin{array}{l}\text { Water depth } \\
\text { maps }\end{array}$ & 100 & $\begin{array}{l}\text { Errors in hydraulic } \\
\text { modelling are not } \\
\text { taken into account; } \\
\text { Measurement errors } \\
\text { in DTM are modelled } \\
\text { by a Gaussian noise } \\
\text { with spatial } \\
\text { auto-correlation. }\end{array}$ \\
\hline $\mathrm{X}_{3}$ & Assets map & 1000 & $\begin{array}{l}\text { Misclassification of } \\
\text { land use types: confusion } \\
\text { matrix; } \\
\text { Variability of ground floor } \\
\text { elevation of assets: empirical } \\
\text { pdf from field survey; } \\
\text { Surface area of polygonal } \\
\text { objects: random multiplying } \\
\text { coefficient drawn from uniform } \\
\text { pdf. }\end{array}$ \\
\hline $\mathrm{X}_{4}$ & $\begin{array}{l}\text { Depthedamage } \\
\text { curves }\end{array}$ & 1000 & $\begin{array}{l}\text { For each depthedamage } \\
\text { curve, random multiplying } \\
\text { coefficient } \varepsilon_{\mathrm{k}} \text { drawn from } \\
\text { uniform pdf } \mathrm{U} 0: 5 ; 1: 5 ; \varepsilon_{\mathrm{k}} \\
\text { are independent. }\end{array}$ \\
\hline
\end{tabular}

${ }^{a}$ One can note that the number $n_{j}$ of random realisations is not the same for each model input: these numbers were chosen under constraints of CPU time and storage space.

\subsubsection{Uncertainty in water depth maps $\left(\mathrm{X}_{2}\right)$}

An in-depth investigation of the uncertainties arising in hydraulic modelling goes well beyond the scope of the present study. Following Bales and Wagner (2009) and Koivum€€ki et al. (2010), who suggest that high-resolution topographic data is the most important input for accurate inundation maps, we focused on one single source of uncertainty in the water depth maps: the measurement and interpolation errors in the $5 \mathrm{~m}$-cell-size DTM. These errors are spatially auto-correlated and are modelled by a Gaussian 2D random field with an exponential variogram model, whose parameters were determined from a set of 500 control field points (sill $17 \mathrm{~cm}$, range $500 \mathrm{~m}$, nugget 0.02 ). A set of $n_{2} 1 / 4100$ random realisations of the random error field is then generated using SGeMS software (Remy et al., 2009), and added as noise to the nominal water depth maps.

\subsubsection{Uncertainty in the assets map $\left(\mathrm{X}_{3}\right)$}

Three uncertainty sources in the assets map are considered: misclassification of polygonal objects, measurement errors in the surface area of assets, and variability of the ground floor elevation of assets. We first built a confusion matrix (Fisher, 1991), based on expert opinion, to account for possible misclassifications in the assets map (Table 4). Next, due to digitalising errorsdabout $0.3 \mathrm{~mm}$ at the map scale (Hengl, 2006), the surface area of polygonal objects in the assets map is uncertain; we thus multiplied the nominal surface of each asset by a corrective random coefficient in $\pm 6 \%$ (uniform pdf). Third, the empirical pdf of ground floor elevation of assets was estimated from a field survey (100 sampled assets, details given in Saint-Geours et al. (2013, Fig. 7)). A total number of $\mathrm{n}_{3} 1 / 41000$ randomized assets map was sampled, combining these three sources of uncertainty. 


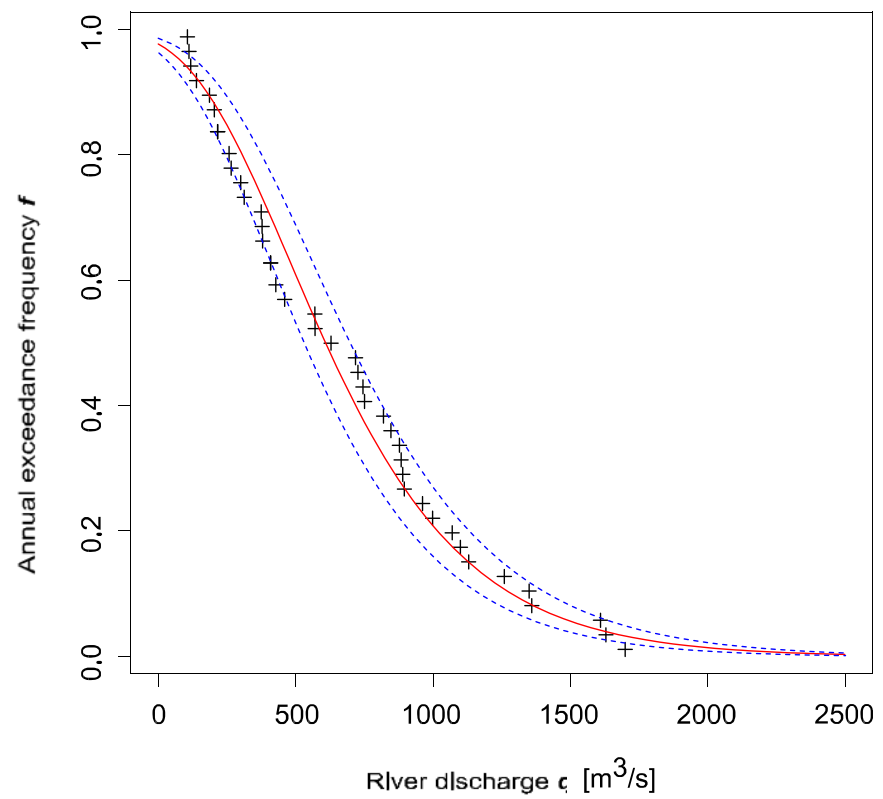

Fig. 5. AMFS dataset from 1967 to 2009 and fitted Gumbel distribution (solid line) with $95 \%$ confidence bounds (dashed lines).

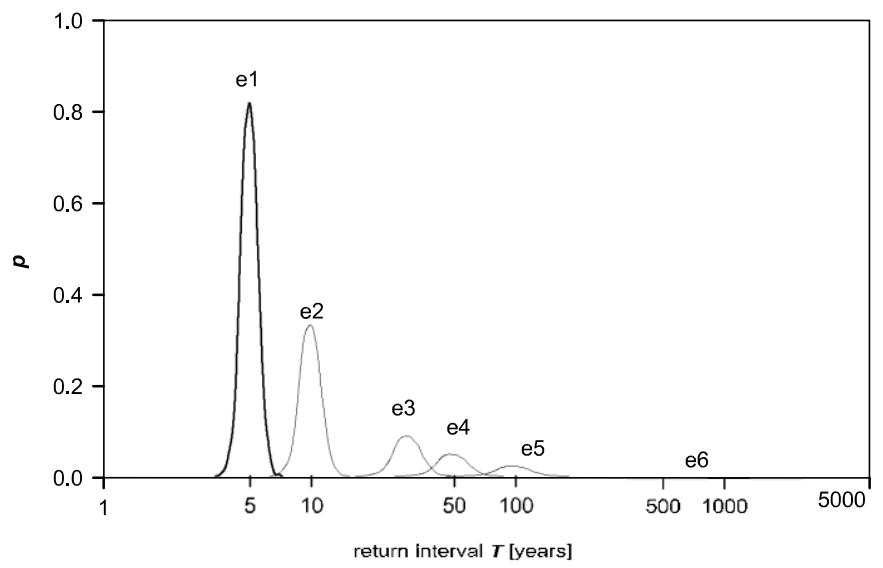

Fig. 6. Empirical distributions of return intervals $T_{i}$ for flood events $e_{1} e_{6}$. Sample size $\mathrm{n}_{1} \frac{1 / 4}{10000 .}$

\subsubsection{Uncertainty in depthedamage curves $\left(\mathrm{X}_{4}\right)$}

Uncertainty in depthedamage curves has been extensively discussed in previous flood damage assessment studies (Koivumaki et al., 2010; Merz et al., 2010; de Moel and Aerts, 2011). Here, we represent the uncertainty on the set of 94 depthedamage curves by a uniform pdf, defining a $50 \%$ to $\mathbf{p} 50 \%$ range around nominal curves (Fig. 7). ${ }^{2}$ Random depthedamage curves associated with each land use type and subtype are sampled independently ${ }^{3}$ (sample size $\mathrm{n}_{4} \frac{1 / 4}{1000)}$.

\footnotetext{
2 The [ 50\%, b50\%] uncertainty range is chosen based on expert opinion. It is in line with Torterotot (1993) who studied the uncertainty on depthedamage curves for private housing and displayed coefficients of variation around $40 \%$. Other authors could choose a much larger range (Merz et al., 2010).

${ }^{3}$ Note that this model of uncertainty is different from that of de Moel and Aerts (2011), who sampled randomized depthedamage curves collectively for all types of assets, from a single p-value. Saint-Geours (2012, p.172) explains how the hypothesis of independence or homogeneity of the depthedamage curves over different types of assets will induce more or less cancelling-out effects at aggregated scales.
}

Table 4

Confusion matrix of the assets map.

\begin{tabular}{|c|c|c|}
\hline Land use type & $\begin{array}{l}\text { Number } \\
\text { of sub-types }\end{array}$ & $\begin{array}{l}\text { Probability of confusion } \\
\text { between sub-types }\end{array}$ \\
\hline Private housing & 1 & No confusion. \\
\hline Cultivated land & 15 & $\begin{array}{l}25 \% \text { chance of confusion } \\
\text { between durum wheat } \\
\text { and bread wheat; } 10 \% \\
\text { chance of confusion } \\
\text { between colza, maize, } \\
\text { barley and sunflower; } \\
25 \% \text { chance of confusion } \\
\text { between permanent and } \\
\text { temporary grassland. }\end{array}$ \\
\hline Campgrounds & 18 & No confusion. \\
\hline $\begin{array}{l}\text { Other economic } \\
\text { activities }\end{array}$ & 60 & $\begin{array}{l}0.17 \% \text { chance of belonging } \\
\text { to each other class of economic } \\
\text { activities. }\end{array}$ \\
\hline
\end{tabular}

\subsection{Propagating uncertainty through the NOE model}

Once each model input has been sampled, uncertainty is propagated through the NOE model using Monte Carlo simulation. Numerous pseudo-Monte Carlo sampling schemes have been suggested in the UA/SA literature to efficiently estimate the share of output variance that is explained by each uncertain model input. In this study, we choose to use the Sobol' sampling scheme (Sobol', 1993), also referred to as the pick and freeze scheme, based on the use of LP-t quasi-random sequences which are known to increase the convergence rate of estimates of high-dimensional integrals (Sobol', 1967). Total sample size is equal to $\mathrm{N}^{1 / 4} \mathrm{n} \$(\mathrm{p} \mathrm{p} 2)^{1 / 4} 24,576$ where $\mathrm{p}^{1 / 4} 4$ is the number of inputs and n $1 / 44096$ is the base size of LP-t quasi-random sequences; it is chosen to be large enough to obtain a satisfactory level of accuracy for the sensitivity indices estimates. The four uncertain model inputs $\mathrm{X}_{1} \mathrm{eX}_{4}$ are assumed to be mutually uncorrelated. The ith line of the quasi Monte Carlo sample is an input set

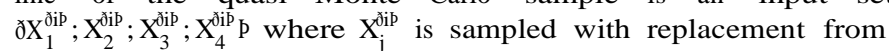
the set of $n_{j}$ pre-generated random realisations of the jth model input. Note that with such large value of $n$, the same realizations of a given input $X_{i}$ can be sampled several times during the experiment. The NOE model is then run for the $\mathrm{N}$ input sets, for a total CPU time of $24 \mathrm{~h}$ on a 6-nodes cluster computer.

\subsection{Variance-based sensitivity indices}

Variance-based total-order ${ }^{4}$ sensitivity indices of each uncertain model input with respect to any output of interest can be estimated from the set of $\mathrm{N}$ model runs, using ad hoc estimators given by Lilburne and Tarantola (2009). These sensitivity indices measure the contribution of a given model input (and its interactions with other inputs) to the variance of a given model output. More precisely, let us consider some model $\mathrm{Y} 1 / 4 \mathrm{f}\left(\mathrm{X}_{1}, \ldots, \mathrm{X}_{\mathrm{p}}\right)$ with $\mathrm{p}$ model inputs. Model inputs $X_{j}$ are treated as independent random variables; hence the model output $\mathrm{Y}$ is also a random variable. The variance-based total-order sensitivity index of $X_{j}$, denoted by $S_{\mathrm{j}}$, measures the share of total output variance $\operatorname{var}(\mathrm{Y})$ that is explained

\footnotetext{
4 In this study, we computed both first-order and total-order sensitivity indices, but we deliberately chose to display only total-order indices for the following reasons: i) preliminary results showed that first-order and total-order indices were close, indicating that interactions between model inputs do not contribute much to model output variance, ii) empirical confidence bounds of total-order indices, computed by bootstrap using 100 replicas, proved to be narrower than that of firstorder indices, and iii) first-order and total-order indices displayed the same behaviour with respect to change of spatial support, which is the focus of our study.
} 


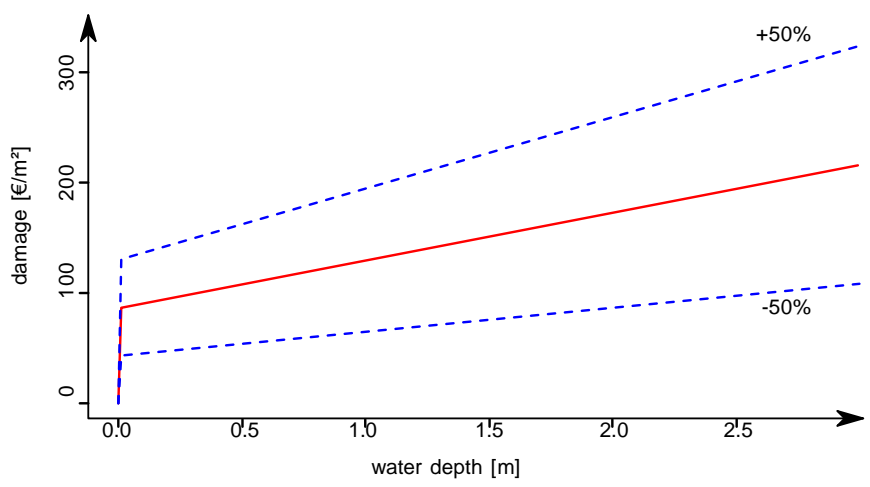

Fig. 7. Nominal depthedamage curve for private housing (solid line) with a [ 50\%; p50\%] uncertainty range (dashed lines).

by model input $X_{j}$ and by the interactions of $X_{j}$ with the other model inputs. It is defined as

$\mathrm{ST}_{\mathrm{j}} 1 / 4 \frac{\mathrm{E} \operatorname{var} \mathrm{YX}_{\mathrm{e}} \mathrm{i}^{\mathbf{i}}}{\operatorname{varðY\mathrm {P}}}$

in which $X_{e_{j}}{ }^{1 / 4} \gamma X_{k} P_{k s j}$ denotes the set of all model inputs but $X_{j}$. Sensitivity $x$ ST $2[0 ; 1]$ is the expected residual part of output variance if all model inputs but $\mathrm{X}_{\mathrm{j}}$ were fixed. The sum of total-order sensitivity indices is always more than 1. Total-order sensitivity indices $\mathrm{ST}_{\mathrm{j}}$ can be used to identify the model inputs that account for most of the model output variability, and they may lead to model simplification by identifying model inputs that have little influence on the model output variance. Please refer to Saltelli et al. (2008) or Plischke (2012) for more details on the definition and estimation of variance-based sensitivity indices.

\subsection{Multi-scale VB-GSA}

To investigate scale issues in the NOE model, we carry out a multi-scale analysis by computing sensitivity indices $\mathrm{ST}_{\mathrm{j}}$ with respect to the aggregated value of the DEAD indicator over different spatial supports of increasing area.

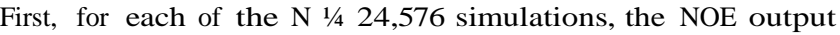
datadi.e., the DEAD indicator computed for each individual asset over the floodplaindis transformed into a number of grid maps of increasing cell sizes: a DEAD grid map is obtained by computing at each cell $c_{k}$ of the grid the sum of the DEAD indicator over all assets (or parts of assets) contained in the cell. ${ }^{5} \mathrm{We}$ consider four different grid maps with cells of $200 \mathrm{~m}$ by $200 \mathrm{~m}, 400 \mathrm{~m}$ by $400 \mathrm{~m}, 800 \mathrm{~m}$ by $800 \mathrm{~m}$ and $1600 \mathrm{~m}$ by $1600 \mathrm{~m}$, and corresponding cell sizes a $1 / 40.04,0.16,0.64$ and 2.56 sq. $\mathrm{km}$, respectively. Fig. 8 shows the DEAD grid maps produced using the nominal values of the NOE model inputs.

Then, grid maps of sensitivity indices are produced by computing total-order sensitivity indices $\mathrm{ST}_{j}$ with respect to the aggregated value of the DEADindicator at each cell of the various DEAD grid maps. More precisely, for each cell size a $1 / 40.04,0.16$, 0.64 , and 2.56 sq. $\mathrm{km}$, and for each model input $\mathrm{X}_{\mathrm{j}}, \mathrm{j} 1 \frac{1}{4} 1, \ldots, 4$, we proceed as follows:

1. at each cell $c_{k}$ of the DEAD grid map of cell size a, we compute the total-order sensitivity index $\mathrm{ST}_{\mathrm{j}}^{\mathrm{a}} \mathrm{\partial c}_{\mathrm{k}} \mathrm{P}$ of the $\mathrm{jth}$ model input

\footnotetext{
5 If an asset has a large surface area and overlaps many cells of the grid, then the value of the DEAD indicator over this asset is shared out among the cells in proportion to the overlaped areas.
}

with respect to the sum of the DEAD indicator over $c_{k}$, from the set of $\mathrm{N}$ model runs;

2. the set of sensitivity indices $\mathrm{fST}_{\mathrm{j}}^{\mathrm{a}} \mathrm{\partial c}_{\mathrm{k}} \mathrm{Dg}$ over all the cells $\mathrm{c}_{\mathrm{k}}$ builds a grid map that we denote by $\mathrm{ST}_{j}^{\mathrm{a}}$ and call sensitivity map of cell size a for the jth model input.

Following this procedure, we obtain $4 \quad 4 \frac{1}{1 / 4} 16$ sensitivity maps $\mathrm{ST}_{j}^{\mathrm{a}}$. Next, in order to compare the sensitivity maps $\mathrm{ST}_{\mathrm{j}}^{\mathrm{a}}$ obtained for various cell sizes a, we summarize each sensitivity map by a single scalar measure. For each cell size a 1/4 0.04, 0.16, 0.64, and 2.56 sq. $\mathrm{km}$., and for the jth model input, we calculate the average value of the sensitivity map $\mathrm{ST}_{\mathrm{j}}^{\mathrm{a}}$, and denote it by $\overline{\mathrm{ST}_{\mathrm{j}}^{\mathrm{a}}}$ :

$\overline{\mathrm{ST}_{\mathrm{j}}^{\mathrm{a}} / / 4} \frac{1}{\mathrm{G}^{\mathrm{a}}}{ }_{\mathrm{k}^{1 / 41}}^{\mathrm{X}} \mathrm{ST}_{\mathrm{j}}^{\mathrm{a}} \mathrm{\partial c}_{\mathrm{k}} \mathrm{p}$

in which $G^{a}$ denotes the total $n$ umber of cells $c_{k}$ in the grid map of cell size a. This average index $\mathrm{ST}_{\mathrm{j}}^{\mathrm{a}}$ is scale-dependent: it measures the average contribution of the jth model input to the variance of the DEAD indicator aggregated over small cells of area a.

Finally, to complete the analysis, we also compute sensitivity indices $\mathrm{ST}_{\mathrm{j}}$ of model inputs $\mathrm{X}_{1} \mathrm{eX}_{4}$ with respect to the aggregated value of the DEAD indicator over the entire floodplain (surface area a $1 / 463$ sq. $\mathrm{km}$.).

\section{Results}

\subsection{Uncertainty analysis}

Fig. 9 shows a spatially explicit representation of the uncertainty on the DEAD grid map over the N 1/4 24,576 model runsdcell size a $1 / 40.04$ sq. $\mathrm{km}$ is taken as an example. A first map displaying the maximum values of DEAD for each cell $c_{k}$ over all model runs (Fig. 9a) is compared to the map of minimum values (Fig. 9b). It appears that for a large number of cells, the minimum and maximum values of DEAD have opposite signs, which we interpret to mean that, due to the uncertainties in the NOE input data, it is impossible to assess with certainty whether these areas will benefit or suffer from the implementation of the flood mitigation measures on the Orb Delta.

By comparing these uncertainty maps with that of land use on the study site (Fig. 3), it can be noted that the cells with uncertain sign are mostly covered with cultivated land and show relatively small values of positive or negative DEAD. On the contrary, for cells $c_{k}$ that include urban areas, campgrounds and other economic activities, the DEAD indicator proves to keep a constant sign over all model runs, with larger positive or negative values. Hence, in spite of the numerous uncertainties that were considered in the analysis, we can conclude that the flood risk management plan will almost certainly result in a reduction of the expected annual damages on urban areas, and almost certainly result in an increase of damages on campgrounds. In addition, cells $c_{k}$ that include urban areas or campgrounds show large standard deviations and low coefficients of variation of the DEAD indicator (Fig. 9c and d), while cells only covered with cultivated land have small standard deviations but larger coefficients of variation.

Table 5 summarises the outcomes of the uncertainty analysis for

each cell size a, as well as for the entire floodplain: it gives the average value (over the cells $c_{k}$ of size a) of the mean, standard deviation and coefficient of variation of the DEAD indicator over $\mathrm{N} 1 / 424,576$ model runs. The mean value and standard deviation of the DEAD indicator naturally increase with the surface area a of the cells over which it is aggregated, ranging from $3.731 \pm 1.380 \mathrm{kV} /$ year for smallest cell size to $5459 \pm 1110 \mathrm{kV} /$ year for the entire 

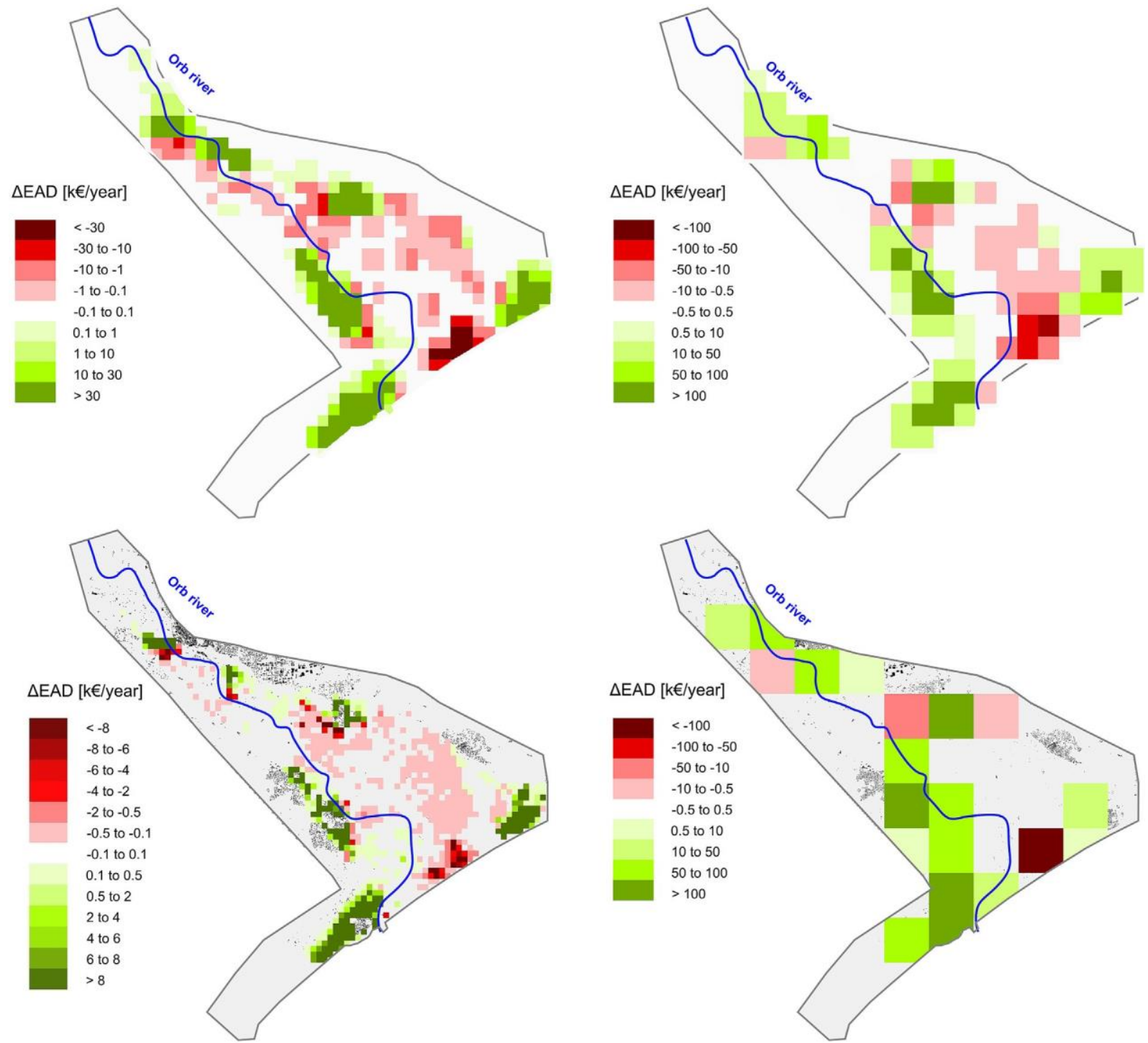

private housing

Orb Delta extent

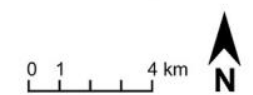

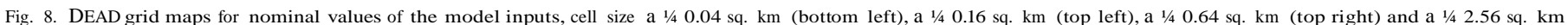
(bottom right).

floodplain. However, if we consider a dimensionless measure of variability such as the coefficient of variation, we observe a different behaviour: the coefficient of variation of the DEAD indicator decreases with the surface area of the cells. This finding corroborates the idea that some spatial averaging-out effects result in a reduction of the relative uncertainty when the DEAD indicator is aggregated over a large spatial unit.

\subsection{Sensitivity analysis}

Fig. 10 displays the sensitivity maps $\mathrm{ST}_{\mathrm{j}}^{\mathrm{a}}$ for each model input and for both the smallest and largest cell size a. Spatial distribution of sensitivity indices proves to be heterogeneous. By comparing the first sensitivity maps (a $1 / 40.04$ sq. $\mathrm{km}$ ) with the map of land use on the study site (Fig. 3), we can identify two different types of areas: urban areas and cultivated land. On the cells that include urban areas, the assets map and the hazard maps display smaller sensitivity indices than on the cells covered with cultivated land.
Correspondingly, depthedamage curves and flood exceedance frequencies have larger sensitivity indices in urban areas than on cultivated land. This finding might be explained by comparing the characteristics of depthedamage curves for private housing assets and agricultural assets. In particular, depthedamage curves for cultivated land are simple step functions with a number of threshold water levels: when water levels are uncertain, they may induce a jump below or above these thresholds. These jumps might explain that the water depth maps have a larger contribution to the variance of the DEAD indicator for cultivated land than for urban areas.

In addition, we can investigate how a change of spatial support modifies the sensitivity indices in the NOE model, by comparing the sensitivity maps $\mathrm{ST}_{j}^{\mathrm{a}}$ for cell sizes a $1 / 40.04$ sq. $\mathrm{km}$ and a $1 / 42.56 \mathrm{sq} . \mathrm{km}$ (Fig. 10 top and bottom, respectively). This comparison clearly suggests that the ranking of uncertainty sources depends on the surface area of the cells. The sensitivity indices of the spatially distributed inputs (i.e., the water depth maps and the assets map) decrease from 

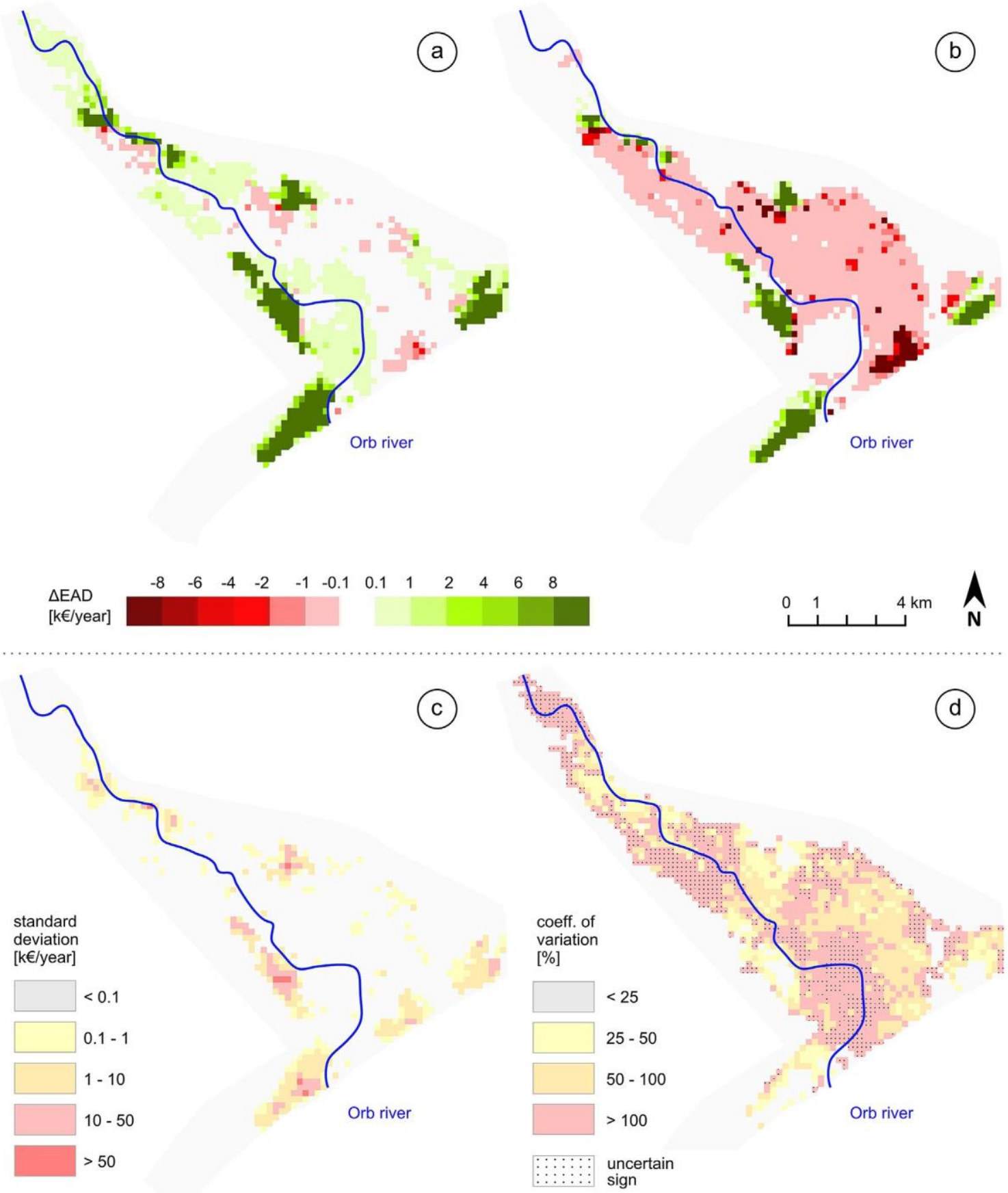

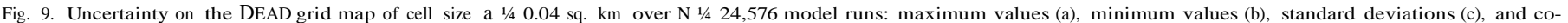
efficients of variation (d) at each cell $c_{k}$. Dashed cells indicate that the sign of DEAD over the cell changes for more than $20 \%$ of model runs.

a $1 / 40.04$ to a $1 / 42.56$ sq. $\mathrm{km}$, while the sensitivity maps of the depthedamage curves and of the flood exceedance frequencies display larger values for cell size a $1 / 42.56$ sq. $\mathrm{km}$ than for a $1 / 40.04 \mathrm{sq}$. $\mathrm{km}$. These results offer empirical evidence of the change of support effect on variance-based sensitivity indices, which was described from a theoretical perspective by Saint-Geours et al. (2012): the sensitivity indices of spatially distributed inputs decrease with the size of the spatial support of model output while the sensitivity indices of non-spatially distributed inputs increase.

To better highlight this change of support effect, Fig. 11 displays the average sensitivity indices $\overline{\mathrm{ST}_{\mathrm{j}}^{\mathrm{a}}}$ [Eq. (3)] for each model input $\mathrm{X}_{\mathrm{j}}$ and each cell size $a$, as well as the sensitivity indices $\mathrm{ST}_{\mathrm{j}}$ for the entire floodplain. From these average indices, one can derive a ranking of model inputs at each cell size: for example, the assets map is ranked 1 st for cell sizes a $1 / 40.05$ to $2.56 \mathrm{sq}$. $\mathrm{km}$., while it is only ranked 3rd for cell size a $1 / 463 \mathrm{sq}$. $\mathrm{km}$. The average sensitivity indices of spatially distributed inputs (i.e., the water depth maps and the assets map) prove to decrease with an increase of the area a over which the model output DEAD is aggregated, while the sensitivity indices of non spatially distributed inputs (depthedamage curves and flood exceedance frequencies) increase contrastingly. For a cell size a $2[5,50]$ sq. km., both spatially and non- 
Table 5

Descriptive statistics over $\mathrm{N}^{1 / 4} 24,576$ simulations: average values ${ }^{\mathrm{a}}$ of mean, standard deviation (s.d.) and coefficient of variation (c.var.) of DEAD over all cells $c_{k}$. Last line gives descriptive statistics for the sum of DEAD over the entire floodplain (one single cell).

\begin{tabular}{lllllll}
$\begin{array}{l}\text { Cell size } \\
\text { a [sq. km] }\end{array}$ & $\begin{array}{l}\text { Number } \\
\text { of cells }\end{array}$ & Av. mean [kV/yr] & Av. s.d. [kV/yr] & Av. c.var. [\%] \\
\hline 0.04 & 1463 & 3.7 & $10^{0}$ & 1.4 & $10^{0}$ & 385 \\
0.16 & 416 & 1.3 & $10^{1}$ & 4.1 & $10^{0}$ & 247 \\
0.64 & 128 & 4.3 & $10^{1}$ & 1.2 & $10^{1}$ & 96 \\
2.56 & 43 & 1.3 & $10^{2}$ & 3.2 & $10^{1}$ & 51 \\
63.00 & e & 5.5 & $10^{3}$ & 1.1 & $10^{3}$ & 20 \\
\hline
\end{tabular}

a The cells $c_{k}$ for which the mean value of the DEAD indicator over $\mathrm{N}$ model runs is nulldi.e., some cells on the edge of the study areadwere not considered to compute these average values.

spatially distributed inputs contribute almost equally to the variance of the DEAD indicator.

In a previous work, Saint-Geours et al. (2012) used a geostatistical framework to provedunder restrictive assumptions of inputs stationarity and model additivity da general relation of the form:

$\mathrm{p} ð \mathrm{aP} \frac{1}{1 / 4} \mathrm{a}_{\mathrm{c}}=\mathrm{a}$

where $p(a)$ is the ratio of sensitivity indices of spatially distributed model inputs vs non spatial inputs, a the area of the spatial unit over which the model output is aggregated, and $a_{c}$ a so-called critical size which depends both on the model characteristics and on the pdf of uncertain model inputs. This critical size divides the range of a into two zones: if $\mathrm{a}<\mathrm{a}_{\mathrm{c}}$, then $\mathrm{p}(\mathrm{a})>1$, which means that sensitivity indices of spatially distributed inputs are larger than those of non-spatial inputs, and thus that spatially distributed inputs are key contributors to model output variability.
Correspondingly, when a $>a_{c}$, non-spatial inputs contribute the most to model output variance. To test this theoretical relation on the NOE model real case study, we computed for each cell size a the ratio $\mathrm{p}(\mathrm{a})$ of the mean value of average sensitivity indices $\mathrm{ST}^{\mathrm{a}}$

and depthedamage curves $\mathrm{X}_{4}$ ):

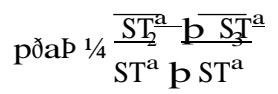

Fig. 12 shows that $\mathrm{p}(\mathrm{a})$ decreases with $\mathrm{a}$, in accordance with Eq. (4). A least squares regression $\left(R^{2} 1 / 40.79\right)$ on log-transformed data points yields an estimate of the critical cell size $\mathbf{b}_{\mathrm{c}} 1 / 46: 72$ sq. $\mathrm{km}$.

\section{Discussion}

\subsection{Sensitivity analysis and spatial averaging-out effects}

Our first goal was to identify the main sources of uncertainty in the NOE model, at different spatial scales. We completed this goal by performing multi-scale VB-GSA on the Orb Delta case study. Our results indicate that for large spatial supports (e.g., the entire floodplain), the main source of uncertainty is the uncertain annual exceedance frequencies of flood events, which explain almost a third of the variance of the DEAD indicator at the floodplain scale. This observation corroborates the conclusions of Apel et al. (2004), who stated that reliable extreme value statistics are crucially important in flood risk modelling. Unfortunately, reducing this input uncertainty is impossible, as it would require longer time series of maximum discharges at gauging stations, which are not available. Besides, we also found that for much smaller spatial
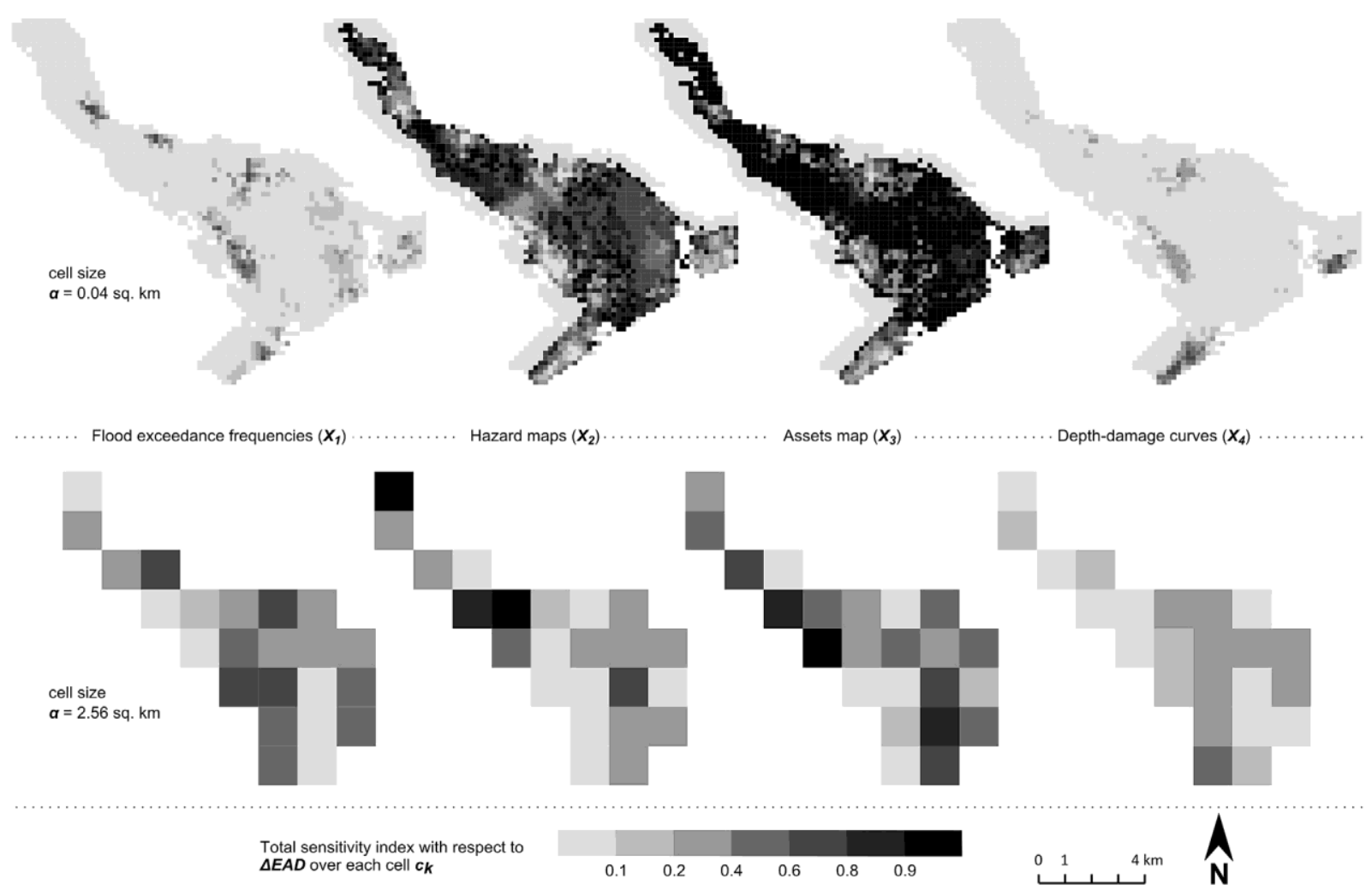

Fig. 10. Sensitivity maps $\mathrm{ST}_{\mathrm{j}}^{\mathrm{a}}$ for each model input $\mathrm{X}_{\mathrm{j}}, \mathrm{j}^{1 / 4} 1, \ldots, 4$, cell sizes a $1 / 40.04 \mathrm{sq} . \mathrm{km}$ (top) and a $1 / 42.56 \mathrm{sq}$. km (bottom). 


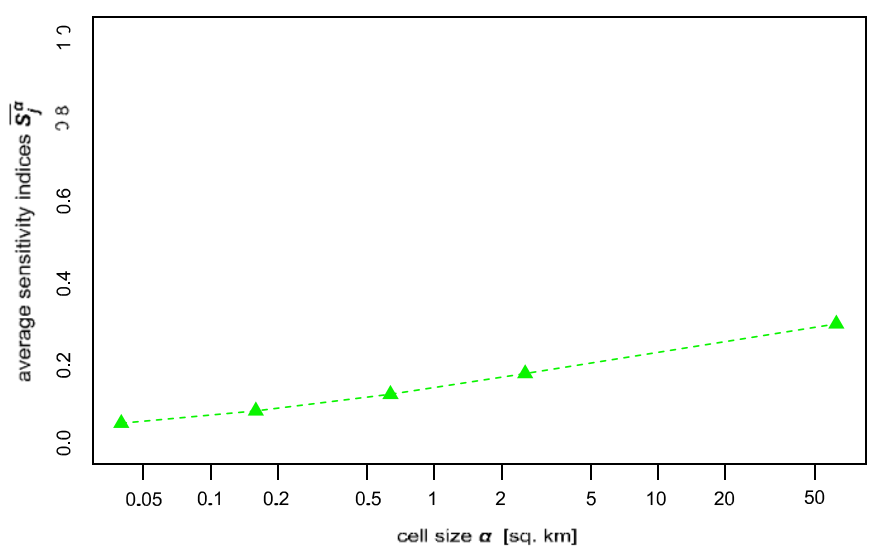

Fig. 11. Average sensitivity indices $\overline{\mathrm{ST}_{j}^{\mathrm{a}}}$ with increasing cell size a (logarithmic scale) for the flood exceedance frequencies $(>)$, the hazard maps $(\mathbf{B})$, the asset map $\left.{ }^{\circ}\right)$ and the depthedamage curves $(\Delta)$. Points on the right hand side of the plot (a $1 / 463 \mathrm{sq} . \mathrm{km}$.) show the sensitivity indices $\mathrm{ST}_{\mathrm{j}}$ with respect to the DEAD indicator aggregated over the entire floodplain.

supports, the variance of the DEAD output indicator is mainly due to the uncertainty on the water depth maps and the assets mapdat the smallest investigated scale (a $1 / 40.04$ sq. km.), these two uncertain inputs explain about $80 \%$ of the output variance.

Hence, our results offer clear evidence that it is impossible to establish a fixed and general ranking of the sources of uncertainty in spatially distributed models. On the contrary, we proved that the ranking of uncertainty sources in the NOE modeldand more generally, in any flood risk modelddepends on the spatial support over which the DEAD output indicator is aggregated. All other things being equal, the relative contributions of the assets map and water depth maps to the variance of the total avoided flood damages over a given zone are a decreasing function of the extent of this zone. This can be explained by a spatial averaging-out effect: the error on water depth maps and the assets map is local, and, if unbiased, it is reduced when it is averaged over a large surface area. Correspondingly, the relative contribution of non spatially distributed inputs (flood exceedance frequencies, depthedamage curves) will increase with the extent of the study area.

These findings offer an empirical confirmation and a better understanding of the previous results of Saint-Geours et al. (2012). They characterized, from a theoretical perspective, the link between spatial averaging-out effects and variance-based sensitivity indices, and summarized it by Eq. (4). Our study shows that this theoretical relation approximately holds on the NOE applied case

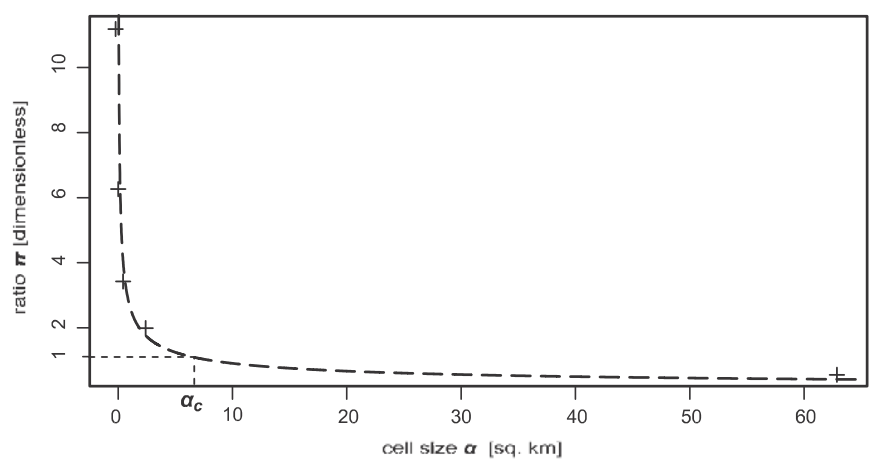

Fig. 12. Ratio $p(a)$ with fitted curve $p(a) 1 / 4 a_{c} / a$. Least squares regression on logtransformed data $\left(R^{2} 1 / 40.79\right)$ yields an estimate of the critical cell size $1 / 46: 72 \mathrm{sq}$. $\mathrm{km}$. study (Fig. 12), even if the restrictive assumptions discussed in (Saint-Geours et al., 2012) are not fulfilleddin particular, NOE uncertain spatial inputs such as water depth maps or the assets map are not stationary random fields. Based on Eq. (4), we could estimate the critical area $\mathbf{b}_{\mathrm{c}} 1 / 46: 72$ sq. $\mathrm{km}$, for which spatially distributed inputs (water depth maps, assets map) and scalar inputs (flood exceedance frequencies, depthedamage curves) contribute equally to the variance of the DEAD indicator.

In practice, flood risk experts often have to choose a spatial scale for the production of output maps, whether they be flood damage maps or, like in the present study, maps of damage reduction brought by a flood risk management policy. Our research yields a better understanding of the following point: the choice of a given resolution (i.e., a spatial support for the aggregation of the flood damage indicator) will determine which sources of uncertainty are the most influential. To produce accurate maps of expected flood annual avoided damages with an horizontal resolution finer than $a_{c}$, one must try first and foremost to reduce the uncertainty on water depth maps and assets map, which are the key sources of uncertainty on small spatial supports. On the contrary, if a flood damage assessment model similar to NOE is used to produce estimates of total expected annual avoided damages over a large floodplain, then the annual exceedance frequencies of flood scenarios will most likely be the key source of uncertainty.

\subsection{Uncertainty maps and sensitivity maps}

Our research also provides an interesting insight on how, for a fixed output scale, sensitivity indices vary in space. We demonstrated the use of uncertainty maps and sensitivity maps on the Orb Delta case study to display spatially explicit measures of output uncertainty and sensitivities.

First, our results prove that the uncertainty on the DEAD indicator is not spatially homogeneous. In particular, the sign of the DEAD indicator is almost certainly constant in some parts of the Orb Delta (urban areas: DEAD $>0$; seaside campgrounds: DEAD $<0$ ), while in other areas (those mostly covered with cultivated land), the sign of the DEAD indicator is highly uncertain. This spatially explicit description of uncertainty brings new information for the model end-user; it is a valuable tool to discuss what level of uncertainty and what type of uncertainty he can tolerate or not. For example, in this case study, the decision-maker could be especially concerned with the absolute standard deviation of the DEAD indicator: he would then pay more attention to urban areas. On the contrary, he could be worried not so much about the DEAD standard deviation, but rather about the DEAD changing sign: in that case he would focus on cultivated land.

To identify which sources of uncertainty contribute the most to the variability of the DEAD maps, we also produced sensitivity maps $\mathrm{ST}_{\mathrm{j}}^{\mathrm{a}}$, in which variance-based total sensitivity indices are computed at each cell of a regular grid. These maps clearly suggest that the contribution of the NOE model inputs to the variance of the DEAD indicator is not spatially homogeneous. For example, the sensitivity indices of the water depth maps and the assets map are smaller in urban areas than in areas covered with cultivated land. Such different ranking of uncertainty sources from one location to another may be explained by a number of factors, including the main land use type at that location, the shape of the associated depthedamage curves, the average water depth at that location, etc. Even if we did not explore this point in depth, the sensitivity maps clearly appear to be promising tools to better explore the behaviour of spatial models. In particular, an interesting question is how to summarize the information contained in a sensitivity map into a single scalar measure. In this exploratory study we simply computed the non-weighted average $\mathrm{ST}_{j}^{\mathrm{a}}{ }^{1 / 4} 1=\mathrm{G}^{\mathrm{a}}{ }_{\mathrm{k}} \mathrm{ST}_{j}^{\mathrm{a}} \partial_{\mathrm{k}} \mathrm{P}$ of 
sensitivity indices defined with respect to the DEAD indicator on each cell $c_{k}$ of the map. However, we could design other average measures, in order to answer the various questions of the model end-user. For example, if the model end-user is mostly concerned with reducing the absolute standard deviation of the DEAD indicator, then he may compute the average of cell-based sensitivity indices $\mathrm{ST}_{\mathrm{j}}^{\mathrm{a}} \partial_{\mathrm{k}} \mathrm{P}$ weighted by the DEAD variance on each cell $c_{k}$. On the contrary, if he is more worried with the DEAD indicator changing signs, he will calculate the average of cell-based sensitivity indices $\mathrm{ST}_{j}^{\mathrm{a}} \partial \mathrm{c}_{\mathrm{k}} \mathrm{P}$ weighted by the proportion of DEAD changing signs over all model runs on the cell $\mathrm{c}_{\mathrm{k}}$. These various average measures would probably give different conclusions on the key model inputs that drive the uncertainty of the DEAD map at a given cell size a. Another idea could be to build up on recent works that investigated the issue of defining and computing sensitivity indices for a functional or multivariate output. Campbell et al. (2006) first suggested to use any dimension reduction technique such as Principal Component Analysis to extract a small number of scalar components $\mathrm{Y}^{(\mathrm{m})}$ from the multivariate output $\mathrm{Y}$, then estimate sensitivity indices $S_{j}^{\text {ðmp }}$ with respect to each of these scalar components. Lamboni et al. (2011) applied this approach to a timedependent output $\mathrm{Y}(\mathrm{t})$, and further defined generalized sensitivity indices $\mathrm{GS}_{\mathrm{j}}{ }_{1 / 4} \mathbf{P} \mathbf{u}_{\mathrm{m}} \mathrm{S}_{\mathrm{j}}^{\mathrm{\partial mp}}$ as a weighted average of indices $S_{j}^{ð \mathrm{mp}}$, in which weights $\mathrm{s}^{\mathrm{m}} \mathrm{u}$ esent the energy content of each $\mathrm{m}$ repr

independent scalar component $\mathrm{Y}^{(\mathrm{m})}$ dsee also Gamboa et al. (2013) for a more formal definition of these generalized indices. It should be possible to adapt these approaches to a spatially distributed output, with particular attention being paid to finding an appropriate dimension reduction technique.

\subsection{Limits}

It should be noted that our work is based on hypotheses that may limit the strength of some of its results.

First, like in any UA/SA study, some sources of uncertainty were identified but not taken into account in the sensitivity analysis of the NOE model, and for those that were considered, the uncertainty modelling and sampling may be open to dispute. Among the ignored sources of uncertainty, we should at least mention: i) the choice of flood events $e_{i}$, their number and their characteristics, and ii) the errors in hydraulic modelling, which are extensively discussed in the literature (de Rocquigny et al., 2010). Another key source of uncertainty is that the state of the whole system under study (land use, hydrologic and hydraulic characteristics of the floodplain, etc.) is assumed to be fixed through the length of time over which the flood risk management plan is evaluated (typically 30 e50 years). Relaxing this hypothesis would open a number of new research questions, and may even challenge the very definition of the EAD and DEAD indicators.

Next, we focused in this study on a spatially distributed model in which the modeller's interest is in the sum of model output over a given spatial support (here, the total DEAD over a spatial unit). We know that we would get similar results with the mean of model output over a given spatial support, as variance-based sensitivity indices are invariant under linear transformation of the output of interest [Eq. (2)]. This is probably the most common case in spatially distributed modelling: other examples of such linear outputs of interest are the average porosity of a piece of soil, or the total rainfall over a catchment. However, some non-additive outputs of interest could also be considered, such as the maximal value of model output over a spatial unit (e.g., maximal pollutant concentration over a lake), or the percentage of a zone for which the model output exceeds a certain threshold. We also focused on a point-based model, i.e., a model for which the computation of the model output (flood avoided damages) at some location uses the value of spatial inputs (water depths, assets map) at that same location only. But non-point-based outputs can be encountered in flood damage assessment models; for example, the damage on a farm located at a given point may depend on the flood intensity parameters at this location but also on a number of induced damages on crops, warehouses or infrastructures, related to flood intensity parameters at other locations (Bre mond et al., 2013). Another example is that of flood damage assessment for roads or energy supply networks, in which the damage on one part of the network heavily depends on the flood impacts on other parts of the network. To our knowledge, no study has investigated the properties of variance-based sensitivity indices with respect to such non-linear or non-point-based outputs of interest: the spatial averaging-out effects that we discussed on the NOE model may not hold in these cases.

\subsection{On the use of SA in environmental modelling}

We would like to conclude this section by a few practical comments on the outcomes of sensitivity analysis in environmental modelling. The main reason given in the literature to justify the use of SA is to reduce the variability of the model output by identifying

the key sources of uncertainty. ${ }^{6}$ However, in our experience, this goal is often difficult to reach because reducing the variability of the key model inputs may be impossible. Nevertheless, SA brings some other invaluable outcomes. First, from a practical perspective, the most challenging step of an UA/SA is to identify and describe the various sources of uncertainty involved in a modelduncertain inputs, modelling assumptions, etc. In our view, this first step is also the most instructive for the modeller. Indeed, by carefully discussing the nature of uncertainty in his model, the modeller will be led to foresee problems that he ignored so far and may come up with new ideas. For example, in the NOE model, investigating the nature of uncertainty in the assets map was a strong incentive to better formalize the spatial overlay procedure that is used to assess flood exposure (Saint-Geours, 2012). Next, SA also offers the opportunity to better understand the behaviour of each submodel of a complex modelling chain, and to promote a shared view of uncertainty treatment with all the different partners involved in a modelling project. Finally, SA has also proven its worth as an aid in better understanding the limits of a model, by giving empirical confidence bounds on the model outputs, and by helping to identify some particular range of input values in which the model has an unexpected behaviour. These are essential outcomes that should help the modeller to decide what use can be done of the model and to what extent he can draw firm conclusions and recommendations on the basis of the model outputs.

\section{Conclusions}

This work was carried out with a view towards promoting the use of sensitivity analysis in model-based spatial decision support systems. Based on a detailed study of the NOE model for economic appraisal of flood risk management policies on the Orb Delta, France, we demonstrated how multi-scale variance-based global sensitivity analysis can give a complementary insight on uncertainty propagation and scaling issues in a spatially distributed model. We built both uncertainty maps and sensitivity maps at different spatial scales. From this case study, we derive the following main conclusions:

\footnotetext{
${ }^{6}$ This rationale is called variance cutting in Saltelli et al. (2008)
} 
1. The uncertainty of the DEAD indicator, and the associated sensitivity indices, are spatially heterogeneous;

2. Our results confirm, on the NOE test case, the theoretical conclusions of Saint-Geours et al. (2012): the ratio of sensitivity indices of spatially distributed model inputs vs non spatial inputs can be approximated by the ratio $a_{c} / a$, where $a$ is the area of the spatial support over which the model output is summed up, and $a_{c}$ is a critical size, specific to each model and each case study;

3. On the Orb Delta case study, the critical size is $a_{c} \times 6.72$ sq. $\mathrm{km}$. On a small spatial support ( 6.72 sq. $\mathrm{km}$ ), variance of the DEAD output indicator is mainly due to the uncertainty in the water depth maps and the assets map (spatially distributed model inputs). On a large spatial support (>6.72 sq. $\mathrm{km}$ ), variance of the DEAD output indicator is mainly due to the uncertainty in the annual exceedance frequencies of flood events and depthedamage curves (non spatial inputs).

Further research is now needed to extend the reach of our study, for instance by exploring the case of non-linear or non-point-based outputs of interest. Another challenging issue is how to communicate clearly to model end-users the outcomes of such a spatial uncertainty and sensitivity analysis, and to turn our results into practical recommendations to further improve the accuracy of flood risk studies.

\section{Acknowledgements}

The authors are grateful to Laurent Rippert (Syndicat Mixte de la Valle e de l'Orb) and Pierre Enjalbert (Syndicat Beziers-la-Mer) for providing the flood-related data. This work has also benefited from the support of Plan Rhone (FEDER funding). Author contributions: N. S.-G, J.-S. B. and F.G. performed the research and analysed the data; C.L., J.-S. B. and F.G. supervised the research; N. S.-G. wrote the paper, J.-S. B. and F.G. proofread and improved it. The constructive comments of four anonymous reviewers are acknowledged.

\section{References}

Apel, H., Merz, B., Thieken, A., 2008. Quantification of uncertainties in flood risk assessments. Int. J. River Basin Manag. 6, 149e162. http://dx.doi.org/10.1080/ 15715124.2008.9635344

Apel, H., Thieken, A.H., Merz, B., Bl6schl, G., 2004. Flood risk assessment and associated uncertainty. Nat. Hazards Earth Syst. Sci. 4, 295e308. http:// dx.doi.org/10.5194/nhess-4-295-2004

Arnell, N.W., 1989. Expected annual damages and uncertainties in flood frequency estimation. J. Water Resour. Plann. Manag. 115, 94e107.

Ascough, J., Maier, H., Ravalico, J., Strudley, M., 2008. Future research challenges for incorporation of uncertainty in environmental and ecological decision-making. Ecol. Model. 219, 383e399. http://dx.doi.org/10.1016/j.ecolmodel.2008.07.015.

Bales, J., Wagner, C., 2009. Sources of uncertainty in flood inundation maps. J. Flood Risk Manag. 2, 139e147. http://dx.doi.org/10.1111/j.1753-318X.2009.01029.x.

Bl6schl, G., Sivapalan, M., 1995. Scale issues in hydrological modelling: a review. Hydrol. Processes 9, 251e290.

Bremond, P., Grelot, F., Agenais, A.L., 2013. Review article: economic evaluation of flood damage to agriculture e review and analysis of existing methods. Nat. Hazards Earth Syst. Sci. 13, 2493e2512.

Campbell, K., McKay, M.D., Williams, B.J., 2006. Sensitivity analysis when model outputs are functions. Reliab. Eng. Syst. Saf. 91, 1468e1472. http://dx.doi.org/ 10.1016/j.ress.2005.11.049.

Cariboni, J., Gatelli, D., Liska, R., Saltelli, A., 2007. The role of sensitivity analysis in ecological modelling. Ecol. Model. 203, 167e182. http://dx.doi.org/10.1016/ j.ecolmodel.2005.10.045.

Chen, Y., Yu, J., Khan, S., 2013. The spatial framework for weight sensitivity analysis in AHP-based multi-criteria decision making. Environ. Model. Softw. 48, $129 \mathrm{e} 140$.

CREM, 2009. Guidance on the Development, Evaluation, and Application of Environmental Models (Technical Report). US Environmental Protection Agency, Council for Regulatory Environmental Modeling. URL: http://www.epa.gov/ crem/library/credguidance 0309.pdf (accessed 05.06.14)

Erdlenbruch, K., Gilbert, E., Grelot, F., Lescouliers, C., 2008. Une analyse coûtbenefice spatialisee de la protection contre les inondations: application de la methode des dommages evites a la basse vallee de l'Orb. Ingenieries Eau-Agric.Territoires 53, 3e20.

European Commission, 2009. Impact Assessment Guidelines. Guidelines SEC(2009) 92.

Fisher, P., Comber, A., Wadsworth, R., 2005. Nature de l'incertitude pour les donnees spatiales. Editions Lavoisier, Paris.

Fisher, P.F, 1991. Modelling soil map-unit inclusions by Monte Carlo simulation. Int. J. Geogr. Inform. Syst. 5, 193e208. http://dx.doi.org/10.1080/ 02693799108927843.

Gamboa, F., Janon, A., Klein, T., Lagnoux, A., 2013. Sensitivity for Multidimension and Functional Outputs. Unpublished results. URL: http://hal.inria.fr/hal-00881112/ en (accessed 05.06.14)

Hengl, T., 2006. Finding the right pixel size. Comput. Geosci. 32, 1283e1298.

Heuvelink, G.B.M., 1998. Uncertainty analysis in environmental modelling under a change of spatial scale. Nutr. Cycl. Agroecosyst. 50, 255e264. http://dx.doi.org/ 10.1023/A: 1009700614041

Heuvelink, G.B.M., Burgers, S.L.G.E., Tiktak, A., Den Berg, F.V., 2010. Uncertainty and stochastic sensitivity analysis of the GeoPEARL pesticide leaching model. Geoderma 155, 186e192. http://dx.doi.org/10.1016/j.geoderma.2009.07.004.

ISIS, 2012. Isis Flow User Guide. URL: www.halcrow.com/isis (accessed 05.06.14).

Koivum€ki, L., Alho, P., Lotsari, E., K氏yhk6, J., Saari, A., Hyypp\&, H., 2010. Uncertainties in flood risk mapping: a case study on estimating building damages for a river flood in Finland. J. Flood Risk Manag. 3, 166e183. http://dx.doi.org/ 10.1111/j.1753-318X.2010.01064.x

de Kort, I.A.T., Booij, M.J., 2007. Decision making under uncertainty in a decision support system for the Red River. Environ. Model. Softw. 22, 128e136. http:// dx.doi.org/10.1016/j.envsoft.2005.07.014.

Lamboni, M., Monod, H., Makowski, D., 2011. Multivariate sensitivity analysis to measure global contribution of input factors in dynamic models. Reliab. Eng. Syst. Saf. 96, 450e459.

Lilburne, L., Tarantola, S., 2009. Sensitivity analysis of spatial models. Int. J. Geogr. Inform. Sci. 23, 151e168. http://dx.doi.org/10.1080/13658810802094995.

Maidment, D., 1993. Handbook of Hydrology. McGraw-Hill, New York.

Marrel, A., Iooss, B., Jullien, M., Laurent, B., Volkova, E., 2011. Global sensitivity analysis for models with spatially dependent outputs. Environmetrics 22, 383e397. http://dx.doi.org/10.1002/env.1071.

Merz, B., Kreibich, H., Schwarze, R., Thieken, A., 2010. Review article on assessment of economic flood damage. Nat. Hazards Earth Syst. Sci. 10, 1697e1724. http:// dx.doi.org/10.5194/nhess-10-1697-2010.

de Moel, H., Aerts, J.C.J.H., 2011. Effect of uncertainty in land use, damage models and inundation depth on flood damage estimates. Nat. Hazards Earth Syst. Sci. 58, 407e425. http://dx.doi.org/10.1007/s11069-010-9675-6.

de Moel, H., Asselman, N., Aerts, J.C.J.H., 2012. Uncertainty and sensitivity analysis of coastal flood damage estimates in the west of the Netherlands. Nat. Hazards Earth Syst. Sci. 12, 1045e1058. http://dx.doi.org/10.5194/nhess 12-1045-2012.

Moreau, P., Viaud, V., Parnaudeau, V., Salmon-Monviola, J., Durand, P., 2013. An approach for global sensitivity analysis of a complex environmental model to spatial inputs and parameters: a case study of an agro-hydrological model. Environ. Model. Softw. 47, 74e87.

Petropoulos, G.P., Griffiths, H.M., Tarantola, S., 2013. A sensitivity analysis of the SimSphere SVAT model in the context of EO-based operational products development. Environ. Model. Softw. 49, 166e179.

Plischke, E., 2012. How to compute variance-based sensitivity indicators with your spreadsheet software. Environ. Model. Softw. 35, 188e191. http://dx.doi.org/ 10.1016/j.envsoft.2012.03.004.

Qi, H., Altinakar, M.S., 2011. A GIS-based decision support system for integrated flood management under uncertainty with two dimensional numerical simulations. Environ. Modell. Softw. 26, 817e821. http://dx.doi.org/10.1016/ j.envsoft.2010.11.006

Remy, N., Boucher, A., Wu, J., 2009. Applied Geostatistics with SGeMS: a User's Guide. Cambridge University Press.

de Rocquigny, E., Soulaimani, A., Morse, B., 2010. Uncertainty in hydrological and hydraulic modeling: editorial introduction. Can. J. Civ. Eng. 37, IIIJeV.

Ruffo, P., Bazzana, L., Consonni, A., Corradi, A., Saltelli, A., Tarantola, S., 2006. Hydrocarbon exploration risk evaluation through uncertainty and sensitivity analyses techniques. Reliab. Eng. Syst. Saf. 91, 1155e1162. http://dx.doi.org/ 10.1016/j.ress.2005.11.056.

Saint-Geours, N., 2012. Sensitivity Analysis of Spatial Models: Application to CosteBenefit Analysis of Flood Risk Management Plans (Ph.D. thesis). Universite Montpellier 2. URL: http://tel.archives-ouvertes.fr/tel-00761032.

Saint-Geours, N., Lavergne, C., Bailly, J.S., Grelot, F., 2012. Change of support in variance-based spatial sensitivity analysis. Math. Geosci. 44, 945e958. http:// dx.doi.org/10.1007/s11004-012-9406-5.

Saint-Geours, N., Lavergne, C., Bailly, J.S., Grelot, F., 2013. Ranking sources of uncertainty in flood damage modelling: a case-study on the costebenefit analysis of a flood mitigation project in the Orb Delta, France. J. Flood Risk Manag. http:// dx.doi.org/10.1111/jfr3.12068. Online first.

Saltelli, A., Ratto, M., Andres, T., Campolongo, F., Cariboni, J., Gatelli, D., Saisana, M., Tarantola, S., 2008. Global Sensitivity Analysis e the Primer. Wiley.

SMVOL, 2011. Programme d'actions de prevention des inondations sur les bassins de l'Orb et du Libron(34) pour les annees 2011 a 2015 (Note de presentation). Syndicat Mixte des Vallees de l'Orb et du Libron.

Sobol', I.M., 1967. On the distribution of points in a cube and the approximate evaluation of integrals. USSR Comp. Math. Math. Phys. 7, 86e112. 
Sobol', I.M., 1993. Sensitivity analysis for non-linear mathematical model. Mat. Model. Comput. Exp. 1, 407e414.

Tarantola, S., Giglioli, N., Jesinghaus, J., Saltelli, A., 2002. Can global sensitivity analysis steer the implementation of models for environmental assessments and decision-making? Stoch. Environ. Res. Risk A 16, 63e76. http://dx.doi.org/ 10.1007/s00477-001-0085-x

Te Linde, A.H., Bubeck, P., Dekkers, J.E.C., de Moel, H., Aerts, J.C.J.H., 2011. Future flood risk estimates along the river Rhine. Nat. Hazards Earth Syst. Sci. 11, 459e473. http://dx.doi.org/10.5194/nhess-11-459-2011.
Torterotot, J.P., 1993. Le coût des dommages dus aux inondations: Estimation et analyse des incertitudes (Ph.D. thesis). Ecole Nationale des Ponts et Chaussees, Paris.

Walker, W., Harremoees, P., Rotmans, J., Van der Sluijs, J., van Asselt, M., Janssen, P., Krayer von Krauss, M., 2003. Defining uncertainty: a conceptual basis for uncertainty management in model-based decision support. Integr. Assess. 4, 5e17. http://dx.doi.org/10.1076/iaij.4.1.5.16466. 